\title{
Benefits of Employing a Personal Response System in a Decision Analysis Course
}

\author{
Rachel Or-Bach \\ The Max Stern Yezreel Valley College, Israel \\ orbach@yvc.ac.il \\ Abstract
}

\begin{abstract}
This paper describes the employment of a Personal Response System (PRS) during a Decision Analysis course for Management Information Systems (MIS) students. The description shows how the carefully designed PRS-based questions, the delivery, and the follow-up discussions; provided a context for eliciting and exercising central concepts of the course topics as well as central skills required for MIS majors. A sample of PRS-based questions is presented along with a description for each question of its purpose, the way it was delivered, the response rate, the responses and their frequencies, and the respective in-class discussion. Lessons from these findings are discussed.
\end{abstract}

Keywords: Personal Response Systems, Clickers, Quantitative methods for decision analysis, Decision Trees, Modeling

\section{Introduction}

Personal Response Systems (PRS) are technologies that enable students to instantly respond to posed questions using a computer or some end user device. PRS is one of several terms used to describe technologies for collecting audience responses. Some of the other terms in use are clickers, polling systems, electronic voting systems, and group/ audience/class response systems. A PRS can receive participants' responses and can provide a representation (or several) of the collected data. Instructors in variety of disciplines are increasingly using PRS to increase participation, engagement and learning (See for example, Beatty \& Gerace, 2009; Mareno, Bremner, \& Emerson, 2010). The use of such systems for education requires respective instructional design regarding the choice and phrasing of the questions, the timing, the frequencies, the representation and presentation of the collected data, further adaptation of instructional interventions according to the collected data, and more.

In line with the assumption that the employment of a PRS should reflect the course goals (Or-

Material published as part of this publication, either on-line or in print, is copyrighted by the Informing Science Institute. Permission to make digital or paper copy of part or all of these works for personal or classroom use is granted without fee provided that the copies are not made or distributed for profit or commercial advantage AND that copies 1) bear this notice in full and 2) give the full citation on the first page. It is permissible to abstract these works so long as credit is given. To copy in all other cases or to republish or to post on a server or to redistribute to lists requires specific permission and payment of a fee. Contact Publisher@InformingScience.org to request redistribution permission.
Bach, 2014), this paper focuses on the employment of a PRS in a Decision Analysis course for Management Information Systems (MIS) students. Along with the use of multiple choice questions which enable immediate representation of the responses for a follow-up discussion, we incorporated questions that require free text responses. This additional style of using the PRS enables insights into students' conceptions 
and misconceptions. The respected analysis can then be presented for triggering reflection processes and thus refining students' understanding.

Courses dealing with decision analysis can have different flavors. Some courses emphasize a descriptive view of human decision making behavior, while others emphasize mathematical modeling. Our course deals mainly with quantitative methods for decision analysis and with decision analysis under uncertainty. The course presents also some psychological aspects of probabilistic thinking and human decision making in order to make students aware of respective known biases. Because the course tends to be technical and involves mathematical procedures, it seemed important to keep the focus on modeling approaches, concepts, context of use, etc. The idea was not to have the students "sink" in the computations, but see the purpose and potential use of the different techniques. We tried also to utilize the course for developing and exercising problem solving skills along with some soft non-technical skills that are considered important for MIS graduates (Lavy \& Yadin, 2013). This course seemed a good opportunity for developing such skills in a context of business-like problems that have real-life flavor including uncertainty, additional required data, need for explicit explanation of the rationale for the decision, etc. The way the course was designed seemed a good context for exercising rigor, logical and resourceful thinking; and for exercising the generation and phrasing of convincing and understandable explanations for the decision making process and result. These communication skills are important for MIS graduates and are required for team work as well as for effective user-centered design. A course on decision analysis is also a context for developing and exercising modeling skills. Modeling is an essential capability for MIS graduates whether as part of a programming task, for modeling a business problem or process, and for modelling additional tasks required within the development process of an information system. The use of decision trees is also an opportunity to show and discuss with the students the power of diagramatic representations for modeling (Bredeweg \& Forbus, 2003), for decision making (Lurie \& Mason, 2007), and for problem solving (Larkin \& Simon, 1987; Moreno, Ozogul, \& Reisslein, 2011). In our course we tried to use or add diagrammatic representations, on top of the required use of decision trees, whenever it was appropriate. The benefits of using diagrams in the related topics of conditional probability and posterior probability were investigated and discussed in several studies (Beitzel \& Staley, 2015; Clinton, Alibali, \& Nathan, in-press).

The following sections include a review on personal response systems for learning, a description of the main characteristics of the Decision Analysis course, and a description of the study goals, tools, and findings. The paper concludes with a summary and discussion section.

\section{Personal Response Systems for Learning}

Personal Response Systems have potential benefits for both teachers and students (Simpson \& Oliver, 2007). For the teachers, they provide immediate feedback about the student learning process and allow the teacher to gauge the overall comprehension of the concepts involved in the material. For the students, it can be effective for engagement in class activities, for promoting interactions among students, for receiving immediate feedback, and for facilitating the active participation of students in the learning process by discussing the different answers given to the questions.

Even though researchers raise the questions whether it is a "teaching innovation or merely an amusing novelty" (Lantz, 2010) and whether it is "empowering or compelling reluctant participators" (Graham, Tripp, Seawright, \& Joeckel, 2007); still most research about the use of PRS in class deal with the empowering potential. For example, studies deal with supporting critical thinking (Molborn \& Hoekstra, 2010), with promoting the acquisition of advanced reasoning skills (DeBourge, 2008), with facilitating the development of problem-solving skills (Levesque, 2011), and with influencing metacognition (Brady, Seli \& Rosenthal, 2013). This empowering 
use spans a variety of subject matters in higher education like Biology (Crossgrove \& Curran, 2008), Computer Science (Fan \& van Blink, 2006), Sociology (Molborn \& Hoekstra, 2010) and Information Literacy (Stagg \& Lane, 2010). Some studies also examined the learning gains as manifested in the students' scores. Bojinova and Oigara (2011) found no significant difference in the class mean final examination scores for students taught with clickers (treatment group) compared to those taught in a traditional class setting (control group). However, the range of final exam scores and final course grades were smaller for the class with clickers compared to the class without clickers. Majerich, Stull, Varnum, and Ducette (2011) found that on average, students who participated in clicker episodes achieved significantly higher scores on the cumulative final examination compared to the other group. Regression analysis was used to control for differences among the students and to quantify the effect of clicker use. The regression results indicated that controlling for all of the entered variables, for every one more clicker episode the student responded to, the final grade was raised by 1.756 points. An interesting finding was that how well the student did on these "clicker quizzes" never proved significant in the regression analyses.

Researchers attribute the success of PRS to the fact that it provides a context for active learning and that questioning provokes deeper cognitive processing in the learner, which in turn results in better learning (Campbell \& Mayer, 2008). The immediate feedback can serve as a motivating factor in focusing student attention and allowing opportunities for review and reflection (Gauci, Dantas, Williams, \& Kemm, 2009). Martyn (2007) mentions two important key features that distinguish the use of PRS from active learning that employs questions and discussion in class. PRS use provides a mechanism for students to participate anonymously, and it integrates a "game approach" that has the potential to engage the students even more than traditional class discussion. The latter fits well with the current research regarding the benefits of gamification (Domínguez Et al., 2013).

Blasco-Arcas, Buil, Hernandez-Ortega, and Sese (2013) developed a conceptual framework, based on quantitative analysis, to explain the positive effects and benefits of clickers in enhancing student learning performance. They suggest that student perceptions of the interactivity with peers and with the teacher that result from using clickers promote active collaborative learning and engagement, which ultimately leads to enhanced learning performance.

What should be added to this framework is the elements of instructional design that address the design of the questions along with the timing for presenting them. Any evaluation, whether formative or summative, forwards a message (usually implicitly) to the students what are the main issues of the topic on hand. The use of the PRS-based activities has the potential to focus the attention of the students to the main concepts and skills. It is important to design the PRS-based activities so that they are spread in a way that enables this focusing goal and also that the PRS is not overused because it might lose its potential for engagement. In this paper we try to demonstrate how the specifics of the course influenced the employment of the PRS-based learning activities to enhance the above processes for better learning.

SMS-HIT (Kohen-Vax, Ronen \& Bar-Ness, 2012) is a personal response system based on mobile devices for SMS and web response provision. The system that was designed for teaching purposes enables the instructor to prepare and enact personal response activities in actual instructional setting for any subject domain. Readymade activities are stored in a repository and could be later on copied, modified and reused. The various types of responses along with the respective processing and presentation, provide opportunities to adapt the activity to the instructional context as characterized by the course, the topic (and a specific sub-topic), stage in the course, students (number, previous knowledge and other characteristics), pedagogical strategy, and more. The SMS-HIT system was used in our study for several types of in-class activities based on multiple choice questions as well as questions that require open - short free text answers. 


\section{The Decision Analysis Course - Main Characteristics}

Courses on decision analysis largely differ in their content and instructional methods. The Decision Analysis course is a mandatory course during the third year in our undergraduate program of the Management Information Systems department. Topics of the course include decision analysis (a decision tree model and its analysis), linear optimization, and a bit on biases in human decision making. We consider it an important course for MIS students especially because of the modeling activities that are the main emphasis of the course. Powell (2001) advocates the importance of teaching modeling in management science. He argues that the heart of Management Science itself is not the impressive array of tools that have been built up over the years (optimization, simulation, decision analysis, queuing, and so on) but rather the art of reasoning logically with formal models. He calls for the teaching of basic modeling skills to business students and we believe that it is even more important for MIS students that should employ modeling skills for even broader range of tasks.

The course is conducted in a computer lab in order to enable in-class exercises that use Excel for modeling activities. Excel "What if" tools and the Solver analysis tool are used for problem solving and decision making. Instructors of management science advocate the use of spreadsheets in management science for developing models and for developing decision support systems (Ragsdale, 2001) and also for engaging students in the learning process (McCloskey \& Busson, 2013).

All the problems that the students encountered for the modeling activities were with the flavor of real-world problems, most of them resembling problems that a business manager might encounter.

The PRS was used in most of the sessions, sometimes more than once but with an attempt not to use it too often. The PRS questions were used to invoke further thinking and reflection for the individual students and to trigger discussions in class regarding the responses. The resulted discussions were expected to promote understanding regarding concepts and processes as well as to illuminate misconceptions. Questions that were designed to trigger prior knowledge, especially with regard to probability concepts, were administered before the respective learning materials. Other questions were administered after the students were presented with worked-out examples. The questions included a remarkable portion of open questions where the students were expected to generate an answer and not just choose from given alternatives. Some of the questions were numerical, such as calculating the expected monetary value for the preferred decision, or finding the optimal solution for a given linear programming problem. Other open-ended questions were text-based, where students had to state the meaning or interpretation of the solution, such as a result of sensitivity analysis. The ability to explicitly explain the solution was an important goal of the course and of the use of the PRS. Such responses can illuminate students' conceptions as well as students' ways of thinking and thus enable the instructor to produce instructional interventions that will promote learning processes. The PRS-based questions were designed with the goal to provide an optimal context for eradicating misconceptions and for reinforcing appropriate conceptions, skills and problem-solving habits.

\section{Procedure of the Study}

The goal of the study was to investigate how the use of the PRS enabled the elicitation of students' misconception or knowledge gaps to better adjust the teaching. Better adjusting the teaching means in this case enhancing the understanding of the learning materials as well as triggering and exercising the more general skills described in the previous section.

Sixty students took the course and participated in the study. All the students did not have any previous exposure to the use of PRS in class. The specific PRS that was used in this study has a standard web-based interface and it is very easy to use. The students are MIS students, so no 
technical problem was expected with regard to the PRS use. The students studied in two randomly assigned groups to fit the size of our computer labs. The two groups could have provided an opportunity for a controlled comparison study regarding the PRS use, but this was not our goal. We did not want to prevent one group from using a tool that might promote learning and we wanted to explore the use of the PRS in the Decision Analysis course and extract as much as possible information for improving the immediate instructional process as well as for future improvements of the course.

The PRS questions included multiple choice questions as well as ones that required short free-text responses. Several content-based types of questions were designed and were administered to the students in class:

1. Questions that relate to prior knowledge. These questions dealt with probability notions that are required for decision making under uncertainty and should be applied during the course section on decision trees. The questions were designed in order to make students re-think about what they had learned during the Probability course, but in a qualitative versus quantitative way. These are two examples:

a. A and B are two events on a probability space. Is it possible that the probability of the intersection of these events will be greater than the probability of A? (Yes/No)

b. A and B are two events on a probability space. Is it possible that the probability of A given B will be greater than the probability of A? (Yes/No)

2. Questions about the contribution of the modeling tool to the process of understanding and defining the problem. An example: "From your experience in the course, did the process of constructing a decision tree help you to understand the given problem?" (Didn't help/helped a little/helped/helped a lot)

3. Questions requiring explanations for intermediate values in the problem solution. An example is "what is the meaning of the value attached to the marked node in the decision tree?"

4. Questions regarding the definition and phrasing of the solution to a given decision problem. These questions were designed to stress the fact that the various calculations are conducted for aiding the decision process; they are not the goal or the solution. Some of the expected solutions were actually a policy that involves sequential decisions to be clearly stated in the solution. An example is an open question "what decision would you recommend for the engineer problem?" (based on a given problem of an engineer that has several development options with uncertain consequences and uncertain repair options)

5. Questions that deal with the effect of the decision framing and other known biases. An example is a question used by Tversky and Kahenman (1983) to discuss biases in probabilistic thinking (and thus in decision making). "Linda is 31 years old, single, outspoken and very bright. She majored in philosophy. As a student, she was deeply concerned with issues of discrimination and social justice, and also participated in anti-nuclear demonstrations. Which of the following is more probable: a. Linda is a bank teller; b. Linda is a bank teller and is active in a feminist movement."

The analysis of the free text responses was conducted during the class break or after class and was presented later in class for follow-up discussion. 


\section{Findings of the Study}

This section describes the findings of the study accompanied with some interpretations and discussion. The findings are based mainly on students' responses to a sample of questions presented in class and delivered by the PRS. It should be noted that the specific PRS that we used preserves anonymity, a fact that has its advantages and also its pitfalls. The anonymity might encourage students to respond even when they are not confident about the answer but it also limits the instructor's ability to track students that even don't try to produce an answer. So for the more complex questions the answer rate was not high. The findings are mainly from the first part of the course (about half the course), a part that dealt with modeling and particularly with the use of decision trees for problem definition and for decision making.

The findings will be presented according to the categorization that was described in the previous section. For each category we will present the findings from the representative examples (as described in the categorization) and also present the follow-up instructional intervention. The findings exhibit the students' conceptions and misconceptions to enable better adaptation of the course and enable further improvements. The description of the follow-up instructional interventions illuminates the benefits of employing the PRS questions in class. The PRS-based questions provide a context for enhancing understanding as well as for enhancing additional important cognitive and meta-cognitive skills.

1. Questions that relate to prior knowledge. For the question regarding the intersection of two events 47 students responded, 34 (72\%) of them gave the correct answer. For the conditional probability question 44 students responded, but only $20(45 \%)$ of them gave the correct answer. Students complained that they did not remember the respective formulas, and this became a good opportunity to guide them in using cognitive aids such as diagrams and such as the construction of relevant concrete examples instead of trying to retrieve a formula. Such cognitive aids are useful also for the student's self-evaluation of their generated answers.

2. Questions about the contribution of the modeling tool to the process of understanding and defining the problem. For the question about constructing the decision tree diagram, 25 students responded and the distribution of responses was as follows: 2 (8\%) students chose "Didn't help", 4 (16\%) chose "Helped a little", 10 (40\%) chose "Helped", 9 (36\%) chose "Helped a lot". Even though most of the students that responded appreciated the aid of the constructing the decision tree for understanding the problem, this was an opportunity to stress for all the students (including those that did not respond) again the idea that constructing a model is an iterative process and that external representations such as diagrams can be very helpful.

3. Questions requiring explanations for intermediate values in the problem solution. The goal of such questions was to make students aware of the exact meaning of the values produced by the employment of the rollback method (folding back the decision tree). The representative example question presented a solved decision tree for a given problem with expected monetary values attached to the nodes after employing the rollback method. The students were expected to state in their own words what the value of a specific marked node expresses. There were 39 responses and the students' responses showed a great difficulty in defining the meaning of the specific value. Some just wrote the value, others explained the type of node (decision node versus a chance node) ignoring the issue of the value. Several students wrote "expected monetary value" without stating of what, again avoiding the exact context of the marked node. Other answers that avoided the context of the marked node addressed the overall solution (the optimal decision). This was a good context to revise and stress the issues of precision and exact meaning on top of un- 
derstanding the mechanism of the rollback method. The precise phrasing was stressed as promoting the student's understanding of the decision making process, as well as enabling better communication with potential clients that require the decisions.

4. Questions regarding the definition and wording of the solution to the decision problem. In the representative example for this type of question, the expected answer was a policy that states a sequence of decisions. Only 21 students answered this question, which might indicate that it was difficult for the students to find the optimal decision and to express it in their own words. Nine responses (43\%) stated the expected monetary value for the optimal decision without mentioning what is the respective decision. Two responses $(9.5 \%)$ were values, but it was not clear how they were calculated and what they stand for. Eight responses $(38 \%)$ stated the optimal initial decision but not the ones that should follow according to the future conditions. Two responses $(9.5 \%)$ stated the optimal initial decision with some not very successful effort to describe a policy. This again was a good context to stress the role of the decision tree for such problems and the usefulness of the decision tree for communicating clearly the problem and its solution to both clients and colleagues.

5. Questions that deal with the effect of the decision framing and other biases. These findings are actually from the same course, but from the previous year because this topic was not addressed yet during the current course. The students were required to answer based on the "Which of the following is more probable: a. Linda is a bank teller; b. Linda is a bank teller and is active in a feminist movement." The total number of responses was 31 ; 17 students (55\%) chose answer "a" and 14 students (45\%) chose answer "b". The results of this voting were presented to the students graphically via the bar diagram produced by the software. It was a good context for bringing up the respective probability concepts and rules and confronting students with their violation of the probability conjunction rule. This confrontation in a course that emphasizes probability calculations for decision making encourages students' reflection processes and adheres nicely with the course learning goals. It served as a context to discuss how humans can be biased by the way a problem is presented.

\section{Conclusions}

The initial goal of using a PRS in class, as reported in the literature, is to engage the students. The design of the PRS questions as well as the context of delivering them, the follow-up activities etc. shape the potential benefits of using a PRS in class. The examples presented in this paper were chosen to show how the PRS use reflected the flavor of our Decision Analysis course. As stated in the introduction of the paper, courses dealing with decision analysis can differ in emphasis and flavor. Such courses for students with mathematical background and orientation tend to be technical and emphasize calculations, or at least this is what the students experience. In our course we tried with the PRS use to make students aware of modeling approaches, see the purpose of the different techniques and be able to explain explicitly the meaning of solutions they generated for given problems. This was the reason for including open-ended questions that trigger discussions on respective interpretations. The participation rate provides some indication of students' engagement, even though there might be students that gave some thought to the presented question and still chose not to respond. The fact that the response rate in our study was lower for the more difficult questions might be evidence for this behavior. The participation rate for the various questions in our study was between $35 \%$ and $90 \%$, which is no doubt better than what usually happens in class when the instructor asks a question and one student says the answer out loud while the others have only started to think about it. Because by using the PRS more students are 
already engaged with the problem details and their own way for approaching the solution, the inclass discussions are much more productive for them and for the whole class.

The benefits of employing the PRS during the course were exploited and exhibited mainly in the follow-up discussions and activities, as experienced by the instructor, but the actual responses enabled this learning process. In the description of the findings in the previous section we tried to demonstrate this. The questions, the responses and the follow-up instructional activities enabled the practice of reflection, critical thinking, estimation, use of cognitive aids (such as visualization), precision (in wording, not just in calculations), and communication (for appropriate explanation to the clients). The fact that the questions that required generation of free text explanations to the solution were so difficult for the students with high rate of incorrect or incomplete answers stresses the need for practicing the communication of the problem-solving process and results. The questions, responses and follow-up discussions were also a context for dealing explicitly with skills of problem analysis and problem solving, and with modeling skills. Willemain $(1994,1995)$ investigated expert modelers in operations research and found that these experts did not focus narrowly on building a model but kept in mind the broad context in which the model would be used. The experts considered issues like where useful data can be found and whether the client could understand the model being developed and act on its results. Beside the practice of the above mentioned important skills, the PRS-based activities were certainly a context for practicing the course topics.

The information gathered by the PRS-based activities is instrumental for the formative evaluation of the course as well as for the future employment of the PRS in the course.

The plan for a future study is to examine the contributions and interplay between immediate feedback and delayed feedback. The use of PRS is often recommended because of the immediate feedback that can be provided (Yourstone, Kraye, \& Albaum, 2008). In our course we intentionally choose a PRS that enables also the use of short open-ended (free text) responses along with the use of multiple choice questions. In the case of open-ended responses, to produce a meaningful feedback that stimulates a relevant class discussion, there is a need for further processing of the responses before showing the results and/or providing feedback. We tried to do this processing during the class break in order to provide a feedback that is not immediate, but still in a time range that the context is not forgotten. It might be interesting to investigate the tradeoffs of immediate and delayed feedback, as well as the instructional advantages of a delayed feedback that might stimulate further reflection.

\section{References}

Beatty, I. D. \& Gerace, W. J. (2009). Technology-enhanced formative assessment: A research-based pedagogy for teaching science with classroom response technology. Journal of Science Education and Technology, 18(2), 146-162. http://dx.doi.org/10.1007/s10956-008-9140-4

Beitzel, B. D., \& Staley, R. K. (2015). The efficacy of using diagrams when solving probability word problems in college. The Journal of Experimental Education, 83(1), 130-145. doi: $10.1080 / 00220973.2013 .876232$

Blasco-Arcas, L., Buil, I., Hernandez-Ortega, B., \& Sese, F. (2013). Using clickers in class: The role of interactivity, active collaborative learning and engagement in learning performance. Computers and education, 62, 102-110. http://dx.doi.org/10.1016/j.compedu.2012.10.019

Bojinova, E., \& Oigara, J. (2011). Teaching and learning with clickers: Are clickers good for students? Interdisciplinary Journal of E-Learning and Learning Objects, 7(1), 169-184. Informing Science Institute. Retrieved from http://www.informingscience.org/Publications/1506 
Brady, M., Seli, H. \& Rosenthal, J. (2013). "Clickers" and metacognition: A quasi-experimental comparative study about metacognitive self-regulation and use of electronic feedback devices. Computers and Education, 65, 56-63. http://dx.doi.org/10.1016/j.compedu.2013.02.001

Bredeweg, B., \& Forbus, K. D. (2003). Qualitative modeling in education. AI Magazine, 24(4), 35-46.

Campbell, J., \& Mayer, R. E. (2009). Questioning as an instructional method: Does it affect learning from lectures? Applied Cognitive Psychology, 23, 747-759. http://dx.doi.org/10.1002/acp.1513

Clinton, V., Alibali, M. W., \& Nathan, M. J. (in-press). Learning about posterior probability: Do diagrams and elaborative interrogations help? Journal of Experimental Education. DOI:10.1080/00220973.2015.1048847

Crossgrove, K., \& Curran, K. L. (2008). Using clickers in nonmajors and majors-level biology courses: Student opinion, learning, and long-term retention of course material. CBE-Life Sciences Education, 7, 146-154. Retrieved from http://www.lifescied.org/content/7/1/146.full.pdf + html

DeBourgh, G. A. (2008). Use of classroom "clickers" to promote acquisition of advanced reasoning skills. Nurse Education in Practice, 8, 76-87.

Domínguez, A., Saenz-de-Navarrete, J., de-Marcos, L., Fernández-Sanz, L., Pagés, C., \& Martínez-Herráiz, J. J. (2013). Gamifying learning experiences: Practical implications and outcomes. Computers \& Education, 63, 380-392. http://dx.doi.org/10.1016/j.compedu.2012.12.020

Fan, K. Y. D., \& van Blink, C. D. (2006). A comparison and evaluation of personal response systems in introductory computer programming. Paper presented at the American Society for Engineering Education Annual Conference, Chicago, Illinois. Retrieved from http://2020engineer.iss.utep.edu/world/Research\%20Literature/2551_A_COMPARISON_AND_EVA LUATION OF_PERSONAL_.pdf

Gauci, S. A., Dantas, A. M., Williams, D. A., \& Kemm, R. E. (2009). Promoting student-centered active learning in lectures with a personal response system. Advances in Physiology Education, 33, 60-71. http://dx.doi.org/10.1152/advan.00109.2007

Graham, C. R., Tripp, T. R., Seawright, L., \& Joeckel, G. L. (2007). Empowering or compelling reluctant participators using audience response systems. Active Learning in Higher Education, 8(3), 233-258.

Kohen-Vacs, D., Ronen, M., \& Bar-Ness, O. (2012). Integrating SMS components into CSCL scripts. Proceedings of the 7th IEEE International Conference on Wireless, Mobile \& Ubiquitous Technologies in Education (WMUTE 2012), 107-111, 27-30 March 2012, Takamatsu, Japan.

Lantz, M. E. (2010). The use of "clickers" in the classroom: Teaching innovation or merely an amusing novelty? Computers in Human Behavior, 26(4), 556-561. http://dx.doi.org/10.1016/j.chb.2010.02.014

Larkin, J. H., \& Simon, H. A. (1987). Why a diagram is (sometimes) worth ten thousand words. Cognitive Science, 11(1), 65-99

Lavy, I. \& Yadin, A. (2013). Soft skills - An important key for employability in the "shift to a service driven economy" era. International Journal of e-Education, e-Business, e-Management and e-Learning, 3(5). DOI: 10.7763/IJEEEE.2013.V3.270

Levesque A. A., (2011). Using clickers to facilitate development of problem-solving skills. CBE Life Science Education, 10(4), 406-417.

Lurie, N. H., \& Mason, C. H. (2007). Visual representation: Implications for decision making. Journal of Marketing, 71, 160-177. doi:10.1509/jmkg.71.1.160

Majerich, D., Stull, J., Varnum, S., \& Ducette, J. P. (2011). Facilitation of formative assessments using clickers in a university physics course. Interdisciplinary Journal of E-Learning and Learning Objects, 7, 11-24. Informing Science Institute. Retrieved from http://www.informingscience.org/Publications/1340 
Mareno, N., Bremner, M. \& Emerson, C. (2010). The use of audience response systems in nursing education: Best practice guidelines. International Journal of Nursing Education Scholarship, 7, 1-17. http://dx.doi.org/10.2202/1548-923X.2049

Martyn, M. (2007). Clickers in the classroom: An active learning approach. Educause Quarterly, 30(2), 7174.

McCloskey, D. W. \& Bussom, L. (2013). Active learning and student engagement in the business curriculum: Excel can be the answer. Journal of Learning in Higher Education, 9(2).

Mollborn, S., \& Hoekstra, A. (2010). "A meeting of minds": Using clickers for critical thinking and discussion in large sociology classes. Teaching Sociology, 38(1), 18-27. http://dx.doi.org/10.1177/0092055X09353890

Moreno, R., Ozogul, G., \& Reisslein, M. (2011). Teaching with concrete and abstract visual representations: Effects on students' problem solving, problem representations, and learning perceptions. Journal of Educational Psychology, 103(1), 32-47.

Or-Bach, R. (2014). Use of personal response systems in higher education - A case study. International Journal of Higher Education, 3(3), 134-141.

Powell, S. G. (2001). Teaching modeling in management science. INFORMS Transactions on Education, $1(2), 62-67$.

Ragsdale, C. T. (2001). Teaching management science with spreadsheets: From decision models to decision support. INFORMS Transactions on Education, 1(2), 68-74. http://dx.doi.org/10.1287/ited.1.2.68

Simpson, V. \& Oliver, M. (2007). Electronic voting systems for lectures then and now: A comparison of research and practice. Australasian Journal of Educational Technology, 23(2), 187-208.

Stagg, A., \& Lane, M. (2010). Using clickers to support information literacy skills development and instruction in first-year business students. Journal of Information Technology Education, 9, 197-215. Informing Science Institute. Retrieved from http://www.informingscience.org/Publications/1297? Source

Tversky, A., \& Kahneman, D. (1983). Extensional vs. intuitive reasoning: The conjunction fallacy in probability judgment. Psychological Review, 90, 293-315.

Willemain, T. R. (1994). Insights on modelling from a dozen experts. Operations Research, 42, 213-222.

Willemain, T. R. (1995). Model formulation: What experts think about and when. Operations Research, 43, 916-932.

Yourstone, S. A., Kraye, H. S., \& Albaum, G. (2008). Classroom questioning with immediate electronic response: Do clickers improve learning? Decision Sciences Journal of Innovative Education, 6(1), 75 88.

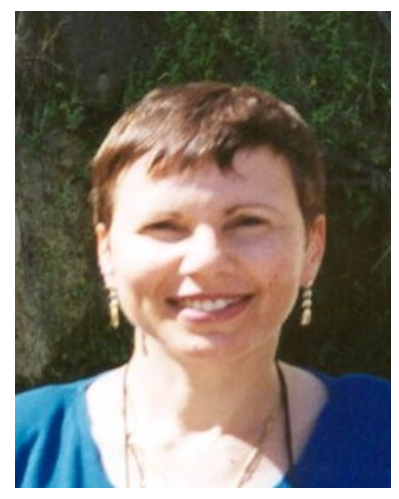

\section{Biography}

Rachel Or-Bach is a senior lecturer in the Management Information Systems department in the Max Stern Yezreel Valley College, Israel. She received her Ph.D. from the Technion-Israel Institute of Technology. Her main research interest is design of interactive learning environments. Her multidisciplinary research is published in journals of information technology for education, science education, computer science and information systems education, informing science etc. 